23

\title{
Оптическая регистрация образования иммунных комплексов с использованием наночастиц коллоидного золота
}

\author{
(C) А.Н. Спицын ${ }^{1}$, Д.В. Уткин ${ }^{1}$, М.Н. Киреев ${ }^{1}$, Н.А. Шарапова ${ }^{1}$, \\ П.С. Ерохин ${ }^{1}$, В.Г. Германчук ${ }^{1}$, В.И. Кочубей ${ }^{2,3}$ \\ ${ }^{1}$ Российский научно-исследовательский противочумный институт „Микроб“ Роспотребнадзора, \\ 410005 Саратов, Россия \\ ${ }^{2}$ Саратовский национальный исследовательский государственный университет имени Н.Г. Чернышевского, \\ 410012 Саратов, Россия \\ ${ }^{3}$ Национальный исследовательский Томский государственный университет, \\ 634050 Томск, Россия \\ e-mail: rusrapi@microbe.ru
}

Поступила в редакцию 10.07.2018 г.

Рассмотрена возможность определения образования иммунных комплексов с использованием антител, меченных наночастицами коллоидного золота и методов оптической спектроскопии. Проведены регистрация и анализ изменения спектральных характеристик золей золотых частиц диаметром 15, 60 и $90 \mathrm{~nm}$, конъюгированных с иммуноглобулинами в присутствии антигенов возбудителей особо опасных инфекций. Полученные данные свидетельствуют о том, что разработанный методический подход оптической регистрации иммунных комплексов может явиться перспективным в создании иммунохимических методов идентификации возбудителей инфекционных болезней.

DOI: 10.21883/OS.2018.11.46848.199-18

\section{Введение}

Спектроскопические методы анализа, основанные на взаимодействии атомов и молекул, входящих в состав вещества, с электромагнитным излучением, могут быть использованы в микробиологических исследованиях для определения высокомолекулярных соединений - корпускулярных антигенов микроорганизмов, содержащихся в исследуемой пробе. В настоящей работе рассмотрена возможность изучения спектров поглощения, прошедшего через клетки излучения, что позволяет получать информацию о биологических молекулах в их составе, обладающих широкими полосами поглощения.

Известно, что для индикации и идентификации возбудителей инфекционных болезней наряду с молекулярногенетическими и бактериологическими методами применяют иммунологические методы диагностики, основанные на реакции взаимодействия специфических антител с антигенами микроорганизмов и выявлении образовавшихся иммунных комплексов [1]. Для оптической и визуальной регистрации специфической иммунологической реакции традиционно применяют антитела с ферментными, флуоресцентными метками или иммобилизованные на различных видах носителей (эритроцитарных, латексных) [2,3]. Измеряется интенсивность сигнала свечения меченых молекул. Однако, несмотря на высокую чувствительность и доступность флуоресцентных меток, такой способ регистрации является фотохимически нестабильным, квантовый выход зависит от окружающей среды и требует наличия дорогостоящих детекторов [4]. В настоящее время представляет интерес использование различных видов наноматериалов для выявления антиге- нов микроорганизмов, характеризующиеся высокой стабильностью и устойчивостью к воздействию различных факторов, изменяющих свои оптические свойства при образовании иммунных комплексов [5]. Так, сферические наночастицы металлов могут применяться в качестве частиц-меток.

Металлические наночастицы обладают свойством поверхностного плазмонного резонанса, когда под действием переменного электрического поля возникают коллективные колебания электронов проводимости [6,7].

Метод иммуноанализа с использованием частиц коллоидного золота (КЗ) является перспективным направлением исследований, в связи с зависимостью спектральных характеристик золей от размеров наночастиц и их конъюгатов с биополимерами. Этот метод основан на свойстве биомолекул, адсорбированных на поверхности металлических наночастиц, сохранять способность вступать в возникающие биоспецифические реакции $[8,9]$. В отличие от иммуноферментного анализа, при использовании наночастиц К3, которые не являются токсичными, отсутствует необходимость дополнительного этапа инкубации с антивидовыми конъюгатами и субстратного проявления комплексов антител с антигеном, отсутствует использование канцерогенных веществ в составе субстрата (ABTS, О-дианизидин). Использование золотых наночастиц в качестве частиц-меток позволило упростить и ускорить методы регистрации эффектов специфического связывания в аналитических системах [10-13]. Белковые молекулы, конъюгированные на наночастицах, вступая во взаимодействие с биоспецифическими парами (реакция антиген-антитело) формируют вторичную биополимерную оболочку, образование которой приво- 
дит к изменению физико-химических свойств золя с последующим изменением цвета [14]. Чувствительность метода регистрации с использованием металлических наночастиц в 60 раз превышает чувствительность применения флуоресцентных меток.

В представленной работе проведена оценка возможности применения антител, меченных КЗ, для оптической регистрации образования иммунных комплексов, а также оптимизация способов выявления специфической реакции и определение критериев дифференциации специфических изменений в результате агрегации и седиментации частиц.

\section{Получение наночастиц КЗ разного диаметра}

Коллоидные растворы металлов могут быть получены различными физико-химическими методами. В наших исследованиях КЗ получали восстановлением золотохлористоводородной кислоты (ЗХВК) цитратом натрия. Метод, предложенный Френсом [15], позволяет получать достаточно стабильные и гомодисперсные золи золота, разные по размеру диаметра частиц от 15 до $90 \mathrm{~nm}$. Для получения стабильных наночастиц золота определенного размера использовали разные концентрации цитрата натрия.

Приготовление золя золота со средним размером частиц 15-17 nm осуществляли следующим образом. В колбу наливали $49.16 \mathrm{ml}$ деионизованной воды, доводили до кипения с обратным холодильником на магнитной мешалке с электроподогревом, далее добавляли $0.5 \mathrm{ml}$ $1 \%$ ЗХВК и увеличивали обороты мешалки, затем до-

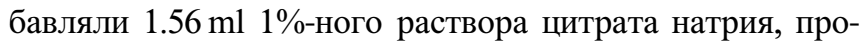
должали кипятить в течение $20 \mathrm{~min}$. Получали раствор красного цвета.

Далее получали К3 с частицами, имеющими средний диаметр 60 и $90 \mathrm{~nm}$. Суть метода, как было описано выше, заключалась в следующем: к кипящему 1\%-ному водному раствору ЗХВК добавляли раствор цитрата натрия в различных концентрациях, изменяемых в зависимости от требуемого размера частиц. Для получения золя золота со средними размерами частиц 60 и $90 \mathrm{~nm}$ использовали меньшие количества раствора цитрата натрия (0.34 и $0.22 \mathrm{ml}$ соответственно) для восстановления 3ХВК.

\section{Отработка условий конструирования конъюгатов наночастиц золота с противочумными иммуноглобулинами}

В качестве иммунореагентов для конъюгации с наночастицами КЗ различного диаметра использовали лошадиную противочумную сыворотку.

Оптимальные для стабилизации золотых наночастиц условия обычно достигаются при возможно более низ- кой ионной силе раствора зонда и значениях $\mathrm{pH}$ на 0.5 единиц выше изоэлектрической точки стабилизирующего вещества. Для достижения таких условий $\mathrm{pH}$ золя золота доводили до 9.0 добавлением $0.2 \mathrm{M}$ раствора карбоната калия. Минимальное защитное количество стабилизирующего вещества мы определяли в иммунологических планшетах с лунками объемом $200 \mu 1$. В тех лунках, где условия среды не были оптимальными по „золотому числу“, происходила агрегация частиц золя после добавления к нему $20 \mu 1$ 10\%-ного раствора хлористого натрия. Агрегация сопровождалась изменением цвета золя с красного на голубой или серый.

После определения минимального количества сыворотки способной полностью стабилизировать золь золотых наночастиц, проводили конъюгацию, причем сыворотку брали в избытке, в объеме примерно на 20\% больше определенного в тесте „золотое число“.

При перемешивании на магнитной мешалке к необходимому количеству иммунореагента добавляли раствор К3 с оптимальным значением рН. Процесс конъюгации длится $15 \mathrm{~min}$. Затем к конъюгату, продолжая перемешивание, добавляли вторичный стабилизатор, 0.5\%-ный раствор полиэтиленгликоля ПЭГ-20000 до конечной концентрация $0.02 \%$ и перемешивали в течение $15 \mathrm{~min}$. Полученный диагностикум выдерживали при температуре $(5 \pm 1)^{\circ} \mathrm{C}$ не менее $1 \mathrm{~h}$.

Определение формы и размеров КЗ и их конъюгатов проводили на сканирующем зондовом микроскопе (C3M) Solver P47-PRO (NT-MDT, Россия) с использованием кремниевых кантилеверов NSG01 (NT-MDT, Россия), напыленных золотом (резонансная частота кантилевера составляла $120 \mathrm{kHz}$, константа жесткости $5.5 \mathrm{~N} / \mathrm{m})$. Исследования выполняли в режиме прерывистого контакта следующими методами: полуконтактным, рассогласования. Образцы препарировали путем нанесения на покровное стекло $4 \mu 1$ суспензии частиц К3 с дальнейшим высушиванием при комнатной температуре.

\section{Экспериментальные измерения}

Проведение спектрофотометрического анализа и регистрация спектральных характеристик золей золотых частиц, конъюгированных с иммуноглобулинами в присутствии антигенов возбудителей особо опасных инфекций, осуществлялось с использованием оптической схемы, представленной на рис. 1.

Разработанная оптическая конфигурация включает источник излучения AvaLight-HAL (Avantes, Нидерланды) со спектральным диапазоном длин волн от 360 до $1700 \mathrm{~nm}$, имеющий разъем SMA 905, оборудованный настраиваемым фокусированием. Свет от источника излучения поступает через входной оптоволоконный кабель (световод) P400-025-SR (Ocean Optics, CША) в пластиковую спектрофотометрическую кювету с длиной оптического пути $10 \mathrm{~nm}$ (Eppendorf, Германия), установленную в держателе кювет CUV-UV/VIS (Avantes, 


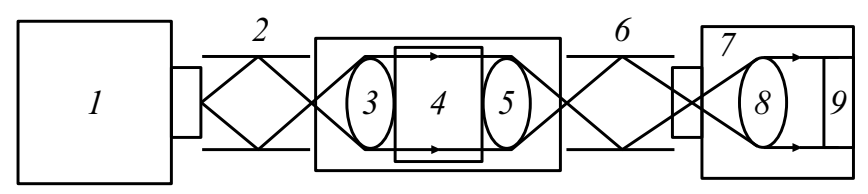

Pис. 1. Оптическая схема проведения спектрофотометрического анализа. 1 - источник излучения, 2, 6 - оптоволоконные кабели, 3,5 - коллимирующие линзы держателя кювет, 4 - кювета, 7 - спектроанализатор, 8 - коллимирующее зеркало спектрометра, 9 - ПЗС-детектор.

Нидерланды), во входных отверстиях которого расположены коллимирующие линзы. Прошедший через образец свет передается по выходному световоду в спектрометр HR4000 (Avantes, Нидерланды) со спектральным диапазоном от 200 до $1100 \mathrm{~nm}$, соединенный с компьютером [16].

В качестве образца сравнения использовался физиологический раствор, что позволило частично учесть поглощение воды в УФ области спектра.

Кюветы с исследуемым материалом (конъюгатами золей золота со взвесями микроорганизмов) поочередно помещали в держатель кювет и регистрировали спектр поглощения раствора. Спектры каждой пробы сохраняли в отдельном файле.

Штаммы $Y$. pestis культивировали на агаре и бульоне Хоттингера ( $\mathrm{pH} 7.2$ ), 3\%-ном кровяном агаре (pH 7.2) при температуре $28^{\circ} \mathrm{C}$ в течение 48 h. Штаммы F. tularensis культивировали на FT-агаре при температуpe $37^{\circ} \mathrm{C}$ в течение $48 \mathrm{~h}$. Агаровые культуры микроорганизмов для проведения исследований снимали петлей и суспендировали в $5 \mathrm{ml}$ физиологического раствора до концентрации, соответствующей 10 единиц отраслевого стандартного образца мутности (ОСО 42-28-85П). Взвеси микроорганизмов обеззараживали в соответствии с СП 1.3.3118-13 [17].

\section{Результаты и их обсуждение}

По данным СЗМ метода исследований размеры золей золотых частиц составили в среднем - 15, 60 и $90 \mathrm{~nm}$. Спектры этих золей имеют пики поглощения с максимумами при длине волны $\lambda$, равные 518,533 и $540 \mathrm{~nm}$ соответственно. Сами же металлические наночастицы имели сферическую и вытянутую (овальную) формы. Следует отметить, что конъюгация золей золота с антителами чумного микроба приводит к смещению максимума поглощения золей в длинноволновую область на 4-8 nm.

Изменение оптических свойств золотых золей обусловлено формированием полимолекулярной оболочки при адсорбции антител на поверхности частиц золота. Адсорбция белка изменяет диэлектрическую проницаемость среды вблизи поверхности наночастиц, и в регистрируемых спектрах поглощения наблюдаются различия по сравнению со спектрами исходных золей [18].
Для оценки возможности применения антител, меченных КЗ, для регистрации образования иммунных комплексов с использованием метода спектрофотометрии исследованы изменения оптических свойств конъюгатов золей с чумными иммуноглобулинами при адсорбции гомологичных антигенов Yersinia pestis. Так, при добавлении взвеси чумного микроба в концентрации $5 \cdot 10^{8} \mathrm{CFU} / \mathrm{ml}$ к раствору биоконъюгата образуется спектр поглощения, представляющий собой сумму спектров поглощения $Y$. pestis и биоконъюгата (рис. 2), обладающего двумя максимумами. Первый пик расположен в области 380-430 nm, который характерен для микробных клеток, а второй пик вблизи максимума поглощения К3 520-540 nm. Для конъюгата антител с золотыми наночастицами размерами 15, 60 и $90 \mathrm{~nm}$ при добавлении взвеси чумного микроба до начала инкубации максимум поглощения наблюдался при длинах волн 519, 536 и $540 \mathrm{~nm}$ соответственно.

После инкубирования смеси в течение $30 \mathrm{~min}$ при температуре $37^{\circ} \mathrm{C}$ наблюдается уменьшение амплитуды коротковолновой полосы поглощения в среднем на $20 \%$ по сравнению с моментом времени до инкубации (рис. 3). Это приводит к видимому сдвигу максимума поглощения, расположенного на $520-540 \mathrm{~nm}$ в длинноволновую область на 2, 2 и $4 \mathrm{~nm}$ для конъюгатов с золотыми наночастицами размерами 15, 60 и $90 \mathrm{~nm}$ соответственно. При этом его оптическая плотность увеличивается примерно на $9 \%$.

Для сравнения были изучены спектральные характеристики взаимодействия конъюгатов золей при добавлении гетерологичных антигенов взвеси Francisella tularensis, взятой в концентрации $1 \cdot 10^{8} \mathrm{CFU} / \mathrm{ml}$ (рис. 4). При данном неспецифическом взаимодействии отсутствует ярко выраженный пик поглощения в диапазоне 380-430 nm, наблюдаемый при образовании комплексов антиген-антитело.

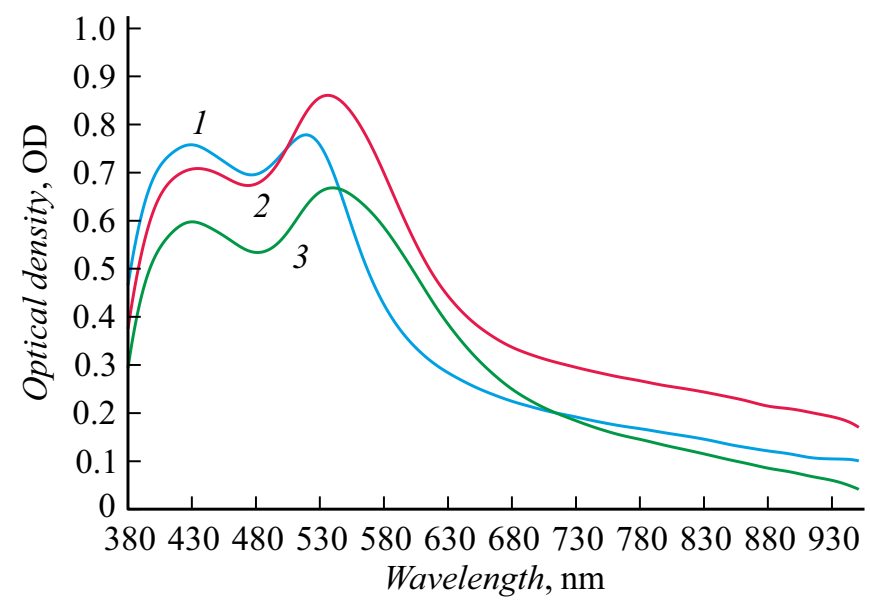

Рис. 2. Спектры поглощения взвесей микроорганизмов $Y$. pestis с иммуноглобулинами чумными, меченными КЗ $(\operatorname{IgAu}) .1-\operatorname{IgAu}(15 \mathrm{~nm})+$ Y'pestis $0 \mathrm{~min}, 2-\operatorname{IgAu}(60 \mathrm{~nm})$ $+Y$. pestis $0 \mathrm{~min}, 3-\mathrm{IgAu}(90 \mathrm{~nm})+Y$. pestis $0 \mathrm{~min}$ 


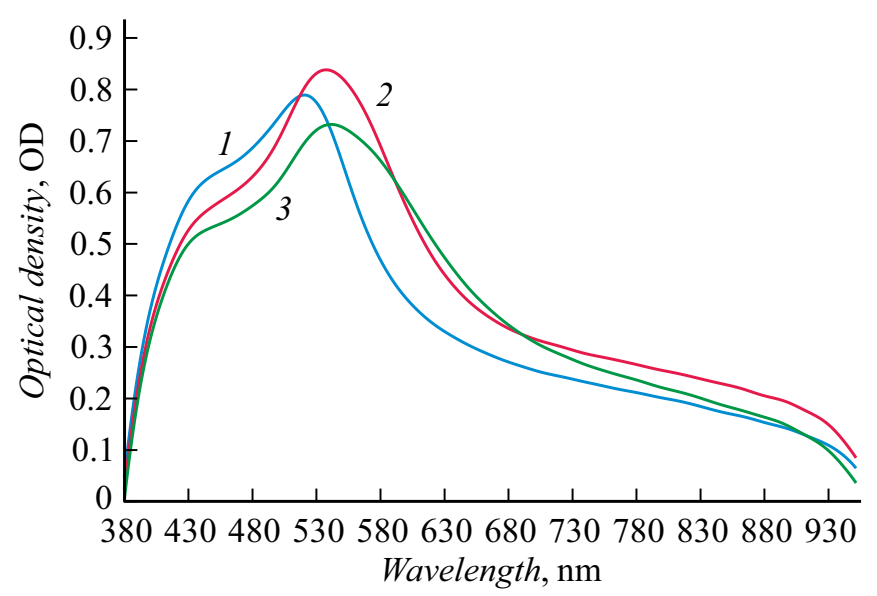

Рис. 3. График изменений спектров поглощения взвесей микроорганизмов Y. pestis после инкубации с иммуноглобулинами чумными мечеными коллоидным золотом (IgAu). $1-\mathrm{IgAu}$ $(15 \mathrm{~nm})+Y$. pestis $30 \mathrm{~min}$ при температуре $37^{\circ} \mathrm{C}, 2-\mathrm{IgAu}$ $(60 \mathrm{~nm})+Y$. pestis $30 \mathrm{~min}$ при температуре $37^{\circ} \mathrm{C}, 3-\mathrm{IgAu}$ $(90 \mathrm{~nm})+$ Y. pestis $30 \mathrm{~min}$ при температуре $37^{\circ} \mathrm{C}$.

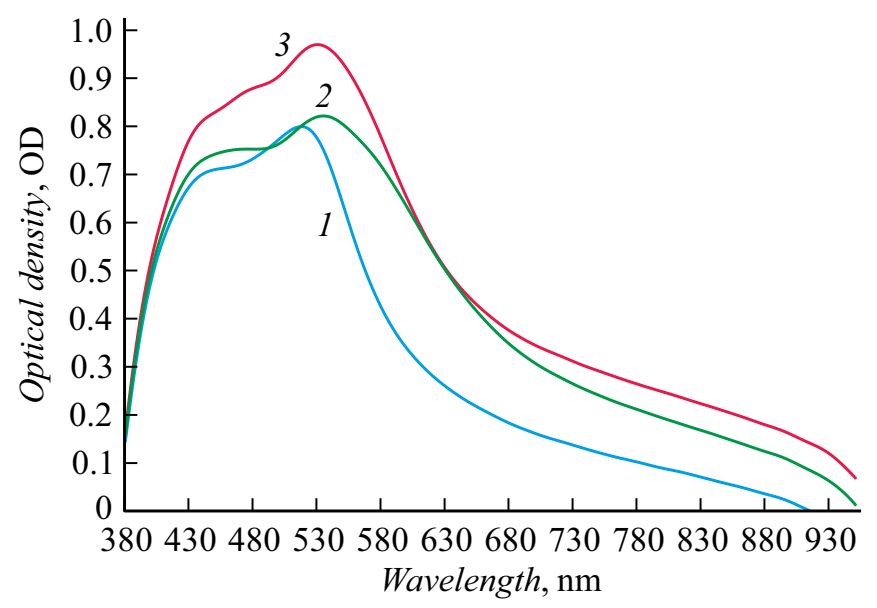

Рис. 4. Спектры поглощения взвесей микроорганизмов F. tularensis с иммуноглобулинами чумными мечеными коллоидным золотом $(\mathrm{IgAu}) .1-\operatorname{IgAu}(15 \mathrm{~nm})+F$. tularensis $0 \mathrm{~min}$, $2-\operatorname{IgAu}(60 \mathrm{~nm})+F$. tularensis $0 \mathrm{~min}, 3-\operatorname{IgAu}(90 \mathrm{~nm})+$ F. tularensis 0 min.

После процедуры инкубации этот пик становится еще более неочевидным, а в области 500-600 nm изменения резонансной полосы не происходит (рис. 5). Происходит снижение оптической плотности среды в коротковолновой области в среднем на $9 \%$.

Наблюдаемое снижение оптической плотности в диапазоне $360-430 \mathrm{~nm}$ объясняется оседанием незначительного количества клеток во время инкубации. Изменение хода кривой поглощения происходит вследствие неспецифического изменения размеров рассеивателей.

Следовательно, характерных изменений в графиках, наблюдаемых при образовании комплекса антигенантитело с КЗ при взаимодействии туляремийного мик- роба и противочумной сыворотки, нет, что указывает на отсутствие специфической реакции.

\section{Выводы}

В результате проведенных исследований получены биоконьюгаты КЗ с антителами против антигенов Yersinia pestis и подобраны условия синтеза, обеспечивающие получение частиц золота со средним размером $15-17,60$ и $90 \mathrm{~nm}$. Изучение спектров поглощения золей в видимой области электромагнитного излучения показало, что при адсорбции антител на наночастицах золота происходит смещение максимума поглощения золей в длинноволновую область на $4-8 \mathrm{~nm}$. Продемонстрирована возможность регистрации специфической реакции взаимодействия антител при инкубации с гомологичными антигенами чумного микроба при помощи спектрофотометрии. В данном случае наблюдается уменьшение амплитуды коротковолновой полосы поглощения на $20 \%$, смещение максимума поглощения, расположенного на $520-540 \mathrm{~nm}$, в длинноволновую область на $2-4 \mathrm{~nm}$ и увеличение интенсивности поглощения на 9\%. При неспецифическом взаимодействии изменений в коротковолновой области и резонансной полосы в диапазоне $500-600 \mathrm{~nm}$ не наблюдается, что может служить критерием отсутствия специфического взаимодействия.

Таким образом, на основании полученных экспериментальных данных можно сделать вывод, что методический прием оптической регистрации образования иммунных комплексов (антиген-антитело), меченных К3, может явиться перспективным подходом в создании иммунохимических методов идентификации возбудителей инфекционных болезней.

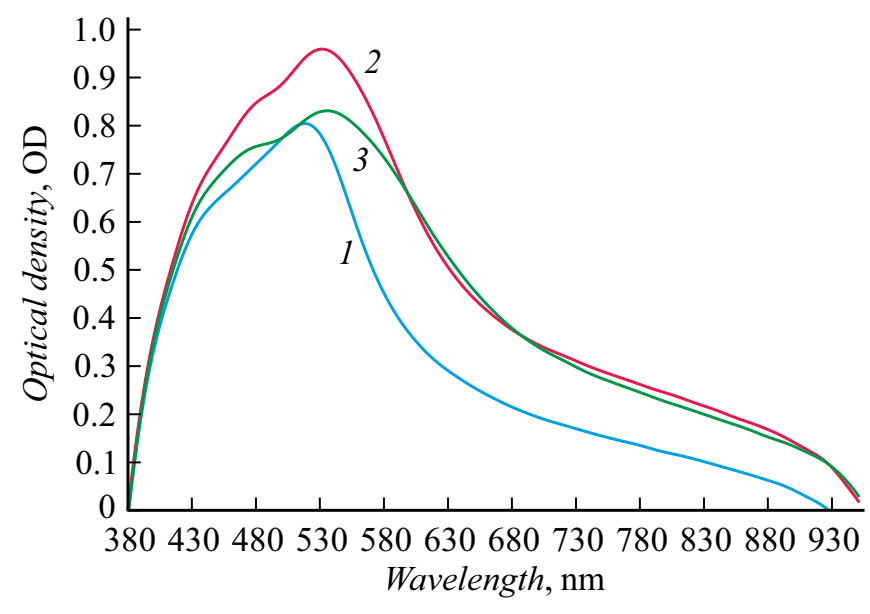

Рис. 5. График изменений спектров поглощения взвесей микроорганизмов F. tularensis после инкубации с иммуноглобулинами чумными мечеными коллоидным золотом (IgAu). $1-\operatorname{IgAu}(15 \mathrm{~nm})+F$. tularensis $30 \mathrm{~min}$ при температуре $37^{\circ} \mathrm{C}$, 2 - IgAu $(60 \mathrm{~nm})+$ F. tularensis 30 min при температуре $37^{\circ} \mathrm{C}$, 3 - $\operatorname{IgAu}(90 \mathrm{~nm})+$ F. tularensis 30 min при температуре $37^{\circ} \mathrm{C}$. 


\section{Список литературы}

[1] Петров Р.В. Иммунология. М.: Медицина, 1987. 416 с.

[2] Специфическая индикация патогенных биологических агентов. Практическое руководство / Под ред. акад. РАН Г.Г. Онищенко, акад. РАН В.В. Кутырева. 2-е изд., переработанное и дополненное. ООО „Буква“, 2014. 284 с.

[3] Бойко А.В., Киреев М.Н., Осина Н.А., Куклев В.Е. // Биотехнология. 2016. Т. 32. № 4. С. 49-55.

[4] Егоров А.М., Гукасов В.М., Иванин А.И., Рубцова М.Ю., Яминский И.В. // Инноватика и экспертиза. 2014. Вып. 2 (13). С. 60-68.

[5] Хлебцов Н.Г., Богатырев В.А., Дыкман Л.А., Хлебцов Б.Н. // Российские нанотехнологии. 2007. Т. 2. № 3-4. C. $69-86$.

[6] Кавецкая И.В., Волошина Т.В., Караванский В.А., Красовский В.И. // Конденсированные среды и межфазные границы. 2009. Т. 11. № 1. С. 53-57.

[7] Henglein A.J. // J. Phys. Chem. 1993. V. 97. N 21. P. 54575471. doi 10.1021/j100123a004

[8] Мальтанова А.М., Пыж А.Э., Ермакова Т.С., Врублевская О.Н., Воробьева Т.Н. // Вестник БГУ. Сер. 2. 2012. № 3. C. 30-34.

[9] Brada D., Roth J. // Anal. Biochem. 1984. V. 142. N 1. P. 79-83. doi 10.1016/0003-2697(84)90518-9

[10] Hayat M.A. // Colloidal Gold: Principles, Methods, and Applications. San Diego, CA: Academic Press. 1989. V. 1. doi 10.1016/C2009-0-21667-9

[11] Schultz S., Smith D.R., Mock J.J., Shultz D.A. // Proc. Natl. Acad. Sci. USA. 2000. V. 97. N 3. P. 996-1001. doi 10.1073/pnas.97.3.996

[12] Thanh N.T.K., Vernhet A., Rosenzweig Z. // Springer Ser. Chem. Sens. Biosens. 2005. V. 3. P. $261-277$. doi $10.1007 / 3-$ 540-27757-9_8

[13] Elghanian R., Storhoff J.J., Mucic R.C., Letsinger R.L., Mirkin C.A. // Science. 1997. V. 277. N 5329. P. 1078-1081. doi 10.1126/science.277.5329.1078

[14] Lazarchik V.A., Vrublevskaya O.N., Vorobyova T.N. // Physics, chemistry and application of nanostructures. 2005. P. 390-393. doi 10.1142/9789812701947_0087

[15] Frens G. // Nature Phys. Sci. 1973. V. 241. N 1. P. 20-22. doi $10.1038 /$ physci241020a0

[16] Уткин Д.В., Германчук В.Г., Глазков А.Н., Ерохин П.С., Спицын А.Н., Задохин С.Н., Щербаков Д.А. // Вестник СГТУ. 2013. № 4 73. С. 49-51.

[17] Санитарно-эпидемиологические правила. Безопасность работы с микроорганизмами I-II групп патогенности (опасности): СП 1.3.3118-13. $180 \mathrm{c}$.

[18] Лазарчик В.А., Врублевская О.Н., Воробьева Т.Н. // Вестник БГУ. 2006. Сер. 2. № 2. 